\title{
In memoriam Paul Josef Hangartner (1948-2020)
}

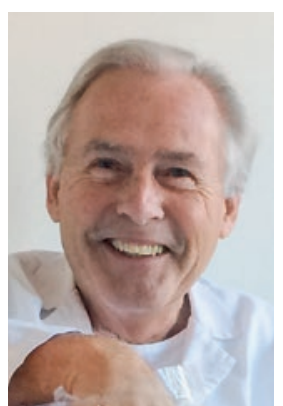

Paul Josef Hangartner
Paul Josef Hangartner wurde Arzt, weil dieser Beruf ein zeitlebens anhaltendes, inneres und ansteckendes Feuer entzündete. Als Internist, Gastroenterologe und Chefarzt erlebte, gestaltete und prägte er seinen Beruf umfassend. Er verstand seine Tätigkeit als Dialog zwischen Arzt und Patient auf Augenhöhe. Der Miteinbezug der Umwelt war ihm als strategisch denkender Mensch eine Selbstverständlichkeit. Er ermöglichte Dinge, in welchen er eine Zukunft erkannte, auch wenn sie bei ihm primär Unbehagen auslösten. Heute würde man rückblickend feststellen: Er verkörperte den strengen und liebenswürdigen Lehrer, den wissenskräftigen und versierten Fachmann, aber auch den gewieften und erfolgreichen Unternehmer, wie wir ihn kaum mehr finden. Von solch kitschigen Betrachtungen hielt Paul Josef selbstredend nichts.

Seine Eltern waren Apotheker und führten den Familienbetrieb in Brunnen, SZ. Zusammen mit den je drei Schwestern und Brüdern verbrachte er eine glückliche Kindheit an der windexponierten Ecke des Vierwaldstättersees, bevor er in die Einsiedler Stiftsschule eintrat. Dieses Umfeld war Wegbereiter für die kultivierte und kontroverse Gesprächskultur, welche die Familie bis heute pflegt. Von Geschwistern im Bereich Pflege, Physik, Musikwissenschaft, Pharmazie, Philologie und Theologie umgeben, wurden seine Weltansichten früh andauernden Prüfungen unterzogen.

\section{Er verstand seine Tätigkeit als Dialog zwischen Arzt und Patient auf Augenhöhe.}

Seine medizinische Karriere begann im Spital Wattwil auf der Chirurgie. Dies allein wäre wohl kaum eine Notiz wert: Allerdings suchte das Spital genau zu diesem Zeitpunkt Verstärkung im Labor. Die mit der Aufgabe betreute Laborantin Edith wurde kurz darauf die Lebenspartnerin und Ehefrau von Paul Josef. In diese frühe Phase des medizinischen Wirkens fällt eine kleine Begebenheit, welche die unbestrittenen Allrounder-Qualitäten des umtriebigen Arztes treffend illustriert:

In Wattwil war man damals als Assistenzarzt auf der Chirurgie in ausserordentlichen Situationen auch für die geburtshilflichen Dienste zuständig. Paul Josef war an jenem Sonntag doppelt überrascht, als er im Operationssaal anlässlich einer Sectio statt eines Kindes gesunde Zwillinge entwickeln konnte.
Die Augen seiner Frau Edith leuchten heute, wenn sie an die Wanderung drei Jahre später denkt. Bei der Wirtschaftseinkehr trat die Wirtin an den Tisch und fragte scheu, ob nicht er der Doktor sei, welcher ihre herzigen zwei Buben auf die Welt gebracht hätte!

Als Schüler von Kollege Siegenthaler blieb Paul Josef zeitlebens der Universität Zürich verbunden. Die fachärztliche Ausbildung in der Gastroenterologie holte er

\section{Ein Vierteljahrhundert prägte er die medizi-} nische Landschaft.

sich bei Kollege Amman, bevor er 1988 als Chefarzt nach Altstätten gewählt wurde. Ein Vierteljahrhundert prägte er fortan die medizinische Landschaft und fungierte zwischenzeitlich gar als CEO der Spitalregion Rheintal Werdenberg Sarganserland. Er war lange Vorstandsmitglied der leitenden Spitalärzte im Kanton St. Gallen, davon 8 Jahre als Präsident. Ich lernte Paul Josef in seiner Funktion als Präsident der Schweizerischen Chefärztekommission der Internisten (heute ICKS*) kennen und schätzen. Die Rücktrittserklärung anlässlich seiner Pensionierung war gleichzeitig der Start für eine fruchtbare Tätigkeit als internistischer Senior Advisor und Gastroenterologe in Stans.

Sein Einsatz im konsumierenden Berufsleben benötigte, wie Franz von Däniken in seinem Nachruf der Absolventen der Stiftsschule Einsiedeln schreibt, ein Korrektiv. Diesen fand er in seiner erfüllten Partnerschaft, lebenslangen Freundschaften und in der Auseinandersetzung mit Kunst, Kultur und Philosophie. Sein letztes Meisterstück gelang ihm als Präsident des Museumsvereins Altstätten mit der Zusammenführung des Kleintheaters und des Museums unter einem Dach. Diesem lokalen Jahrhundertprojekt kommt mittlerweile eine weit überregionale Bedeutung zu. Lieber Paul Josef: Edith vermisst dich im Haus, wo der Flügel an grosse und stimmige Momente erinnert. Wir vermissen dich im Spital. Wir erinnern uns an deine kritische und ordnende Stimme und hätten gern weiter diskutiert. An einer Vernissage hast du die Frage gestellt, was eigentlich Kunst sei. Die Antwort hast du mit einem Zitat von Goethe gleich selbst gegeben: Kunst ist eine Vermittlerin des Unaussprechlichen - vermittelt hast du lebenslang.

Dr. med. Christoph Knoblauch Chefarzt Medizin, Kantonsspital Nidwalden 